\title{
On board LNG reliquefaction technology: a comparative study
}

\author{
J. Romero Gómez, Ph. D., \\ M. Romero Gómez, Ph. D., \\ R. Ferreiro Garcia, Prof., \\ A. De Miguel Catoira, Ph. D., \\ University of A Coruna, Spain
}

\begin{abstract}
Reliquefaction technologies are being currently applied on board liquefied natural gas (LNG) carriers on the basis of economic criteria and energy efficiency. A variety of reliquefaction techniques have been developed so far during the last decade. Nevertheless, technology enhancement continues being a research area of interest. In this article the different technologies applied to the reliquefaction of the boil-off gas (BOG) on LNG carriers have been described, analysed and discussed, contributing to highlight the process and operation characteristics as well as selection plant criteria. Finally, a comparison of the different reliquefaction plants, considering their capacities and efficiencies as well as other technical data of interest has been carried out.
\end{abstract}

Key words: reliquefaction; boil-off gas; vessel; Brayton Cycle; efficiency

\section{INTRODUCTION}

Among merchant ships, the LNG carriers are of the highest speed, their average service speed varies usually in the range of $19 \div 21$ knots [1]. Since the introduction of LNG transport ships, steam turbines have almost exclusively been the method of propulsion. This is namely due to the simplicity of using the gas from the evaporation of the cargo in steam boilers to produce steam for the turbines, while controlling the pressure in the cargo tanks. The overall efficiency of this method is estimated to be of around $30 \%$ [2].

In recent years, due to the increasing cost of LNG, the shipbuilding industry has called for alternative propulsion systems to the steam turbine, opting for more efficient propulsion systems.

Thanks to recent technological developments, electric propulsion with dual 4-stroke engines has become the most demanded option for LNG carriers between 140,000 and $210,000 \mathrm{~m}^{3}$. The use of 2-stroke engines in combination with the BOG reliquefaction is the most used on larger vessels. Electric propulsion with 4-stroke dual-powered engines and the propulsion of 2-stroke engines combined with reliquefaction provide efficiencies above $40 \%$ (43\% and $48 \%$ respectively) [2], while reducing emissions to the atmosphere of NOx, SOx and $\mathrm{CO}_{2}$. Fig. 1 shows the possible propulsion options for LNG carriers depending on the method of processing the BOG.

The implementation of reliquefaction techniques on board has acquired a very important role in recent years, in an effort to reduce operating costs and increasing energy efficiency in large LNG carriers. Despite this, there has been no literature with a detailed technical report in the academic field wherein a comparative description of reliquefaction plants currently on the market is carried out. Although some studies [3, 4] have described the process, the scope of studies is limited to only some characteristics or, in particular, the analysis of the operating cycle. The efforts undertaken in the development and implementation of this new technology installed on board Qatargas 2 in the Q-Flex and Q-Max ships are reviewed in [5]. By means of performing a thermodynamic study, in [6] the conditions, parameters and energy consumption required in the process of reliquefaction on board under the Brayton cycle were analysed and evaluated, including the influence of the choice and variation of diverse factors on the operating conditions and power. A design of the reliquefaction process based on the Brayton cycle is carried out in [7], followed by dynamic simulations for all operation modes. [8] analyses the availability and security of propulsion systems with reliquefaction for LNG vessels along with other studied alternatives to propulsion.

The optimization of redundancy and the maintenance strategy of reliquefaction systems are studied in [9] to provide reliability and reduce costs in case of system failure.

A comparison of the various technologies implemented onboard has become necessary as a result of the increasing number of manufacturers who seek to apply these new techniques on ships in order to reduce operating costs and increase efficiency. In the following sections of this paper a general reliquefaction technology on board is carried out as are the processes of reliquefaction technology already in place, a comparative study of available technologies and the study's con clusions. 


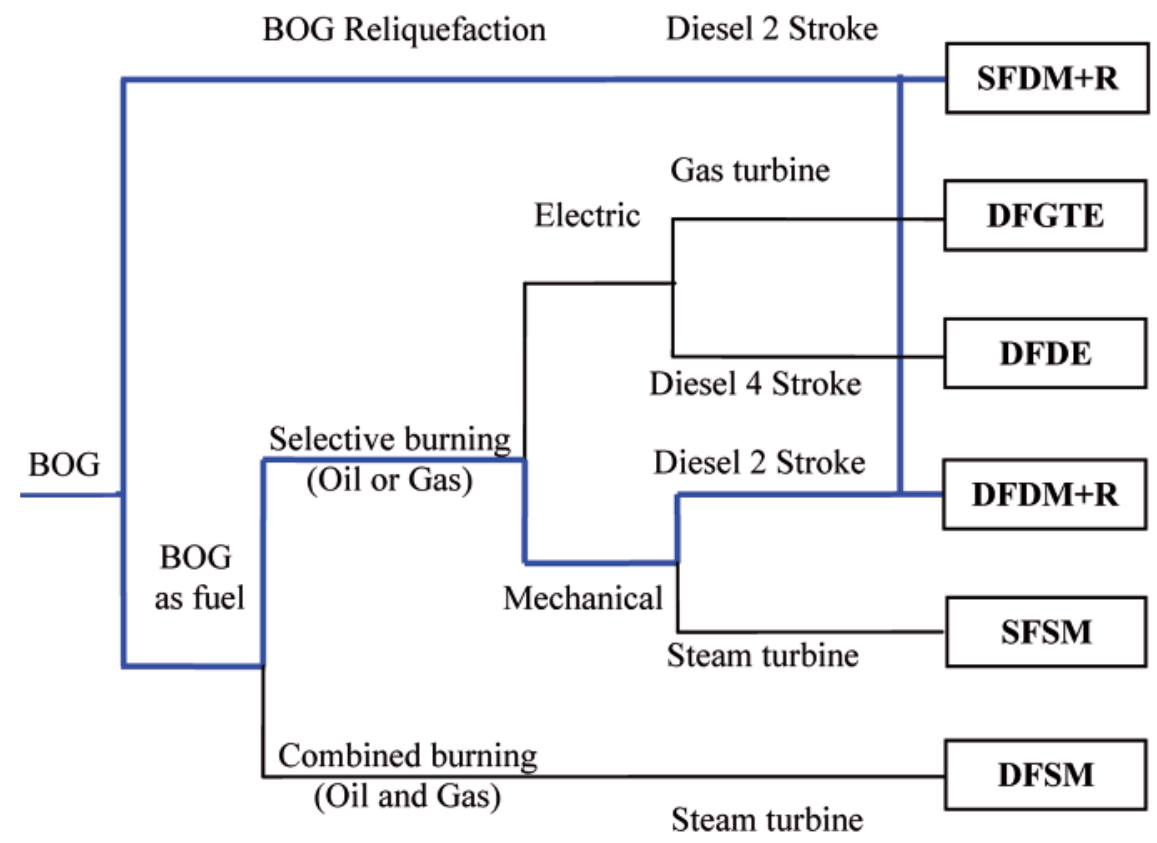

Fig. 1. Different propulsion systems for $L N G$ carriers
Single Fuel Mechanical

with Reliquefaction

Dual Fuel Gas Turbine Electric

Dual Fuel Diesel Electric

Dual Fuel Diesel Mechanical with Reliquefaction

Single Fuel Steam turbine mechanical

Dual Fuel Steam turbine mechanical

\section{RELIQUEFACTION TECHNOLOGY ON BOARD}

The reliquefaction of BOG on board has different processing requirements to traditional LNG plants on shore. While the thermodynamic efficiency of liquefaction plants on-shore is the most contentious criteria, other different factors are more important in re-liquefied projects on board. Therefore, when selecting the reliquefaction technology, several key points should be analysed that outweigh the efficiency of the process and determine the election:

- The limited space on board requires the plant to be compact and lightweight.

- The conditions at sea shouldn't effect the operation of the plant. It must be stable with swaying and pitch.

- Must provide high security and inherent reliability in the process.

- Quick startup with high availability and operability.

- Small amount of equipment, easy installation and low cost.

- Easy maintenance.

a)

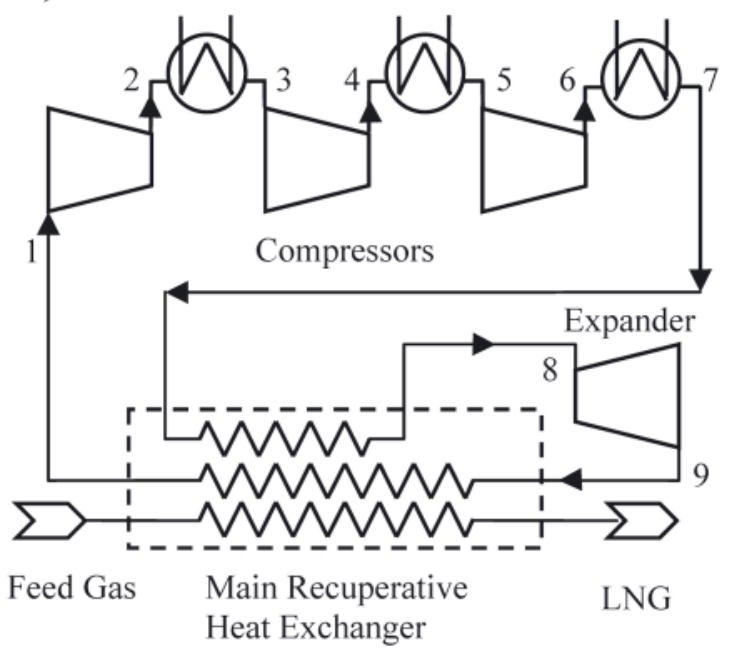

It is because of the above points that the leading manufacturers of this technology incline towards the Brayton cooling cycle (with $\mathrm{N}_{2}$ as the working fluid), instead of other more efficient technologies installed in onshore LNG trains such as:

- Traditional waterfall cycle or mixed refrigerants.

- Simple mixed refrigerant cycle.

- Pre-cooling propane cycle and mixed refrigerant.

These technologies operating onshore reach extremely low rates of liquefaction consumption, around $0.3 \mathrm{kWh} / \mathrm{kg}$ [10].

\subsection{Basic principles of operation of the Brayton cooling cycle}

The Brayton cooling cycle is the inverse of the closed Brayton power cycle. A basic representation of the reverse Brayton cycle used for on board reliquefaction is shown in Fig. 2.

The working fluid is $\mathrm{N}_{2}$ as a number of conditions need to be met that make it ideal for the process. The boiling point of

b)

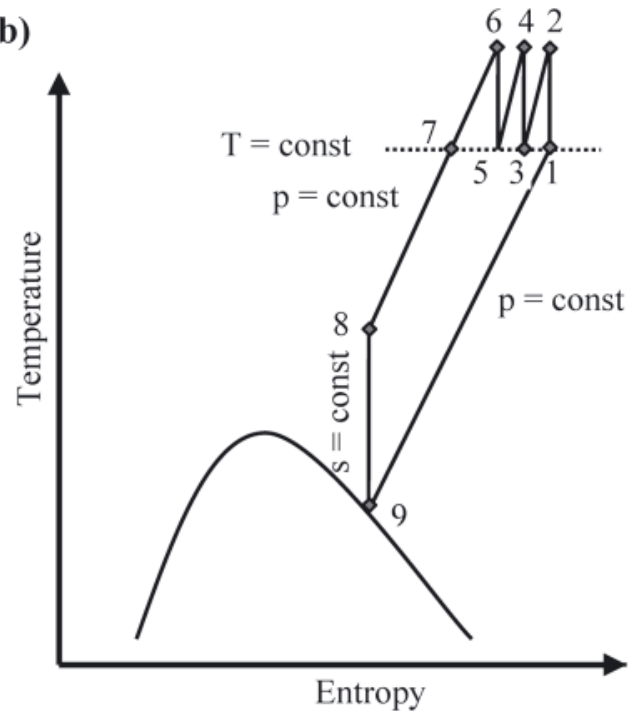

Fig. 2. Schematic diagram of the reverse Brayton Cycle. a) the plant structure, b) the T-S diagram 
the $\mathrm{N}_{2}$ is below methane, it is inert, not a fuel, it's safe and it's acquirement is possible on board.

The working cycle is described as follows: $\mathrm{N}_{2}$ is compressed in stages with intercooling, process 1-7 as shown in Fig. 2. The intercoolers, with sea water or a medium fluid necessary to reduce the compression work.

After the final cooling in the compression, the nitrogen is sub-cooled countercurrent (stage 7-8) with the same $\mathrm{N}_{2}$ in an exchanger. At this temperature it undergoes an isentropic expansion in an expander (stage 8-9), thereby obtaining the cold current to liquefy the BOG and sub-cool the nitrogen before expansion, while recovering a percentage (about 20\%) of power expended in the compression of nitrogen.

\section{RELIQUEFACTION PLANT STRUCTURES IMPLEMENTED ON BOARD}

Current technology of BOG reliquefaction offers seven different processes for LNG carriers. These are listed in Tab. 1 alongwith the company, year of implementation, work cycle and licensor. It is noted that Hamworthy Gas System (HGS) is the manufacturer with most technological influence and that the Brayton refrigeration cycle predominates over other alternatives used.
Tab. 1. Current technology for reliquefaction of BOG on LNG carriers

\begin{tabular}{|c|c|c|c|}
\hline Plant model & Manufacturer & Work Cycle & Year \\
\hline LNG Jamal & Osaka Gas & Inverse Brayton & 2000 \\
\hline TGE & Tractebel & Inverse Brayton & 2004 \\
\hline Mark I & HGS & Inverse Brayton & 2006 \\
\hline EcoRel & Cryostar & Inverse Brayton & 2008 \\
\hline Mark III & HGS & Inverse Brayton & 2008 \\
\hline Mark III Laby-GI & HGS & Inverse Brayton & 2009 \\
\hline TGE Laby-GI & Tractebel & Waterfall & 2009 \\
\hline
\end{tabular}

\subsection{LNG Jamal}

The first reliquefaction plant on board a LNG carrier was installed in the Jamal with a cargo capacity approaching $135.000 \mathrm{~m}^{3}$ [11]. It was intended to pave the way toward the use of new propulsion systems and better the efficiency in the transport of LNG. Due to lack of experience with the implementation of reliquefaction technology on board, a steam turbine plant with a propulsion system was installed instead of the other possible more efficient systems.

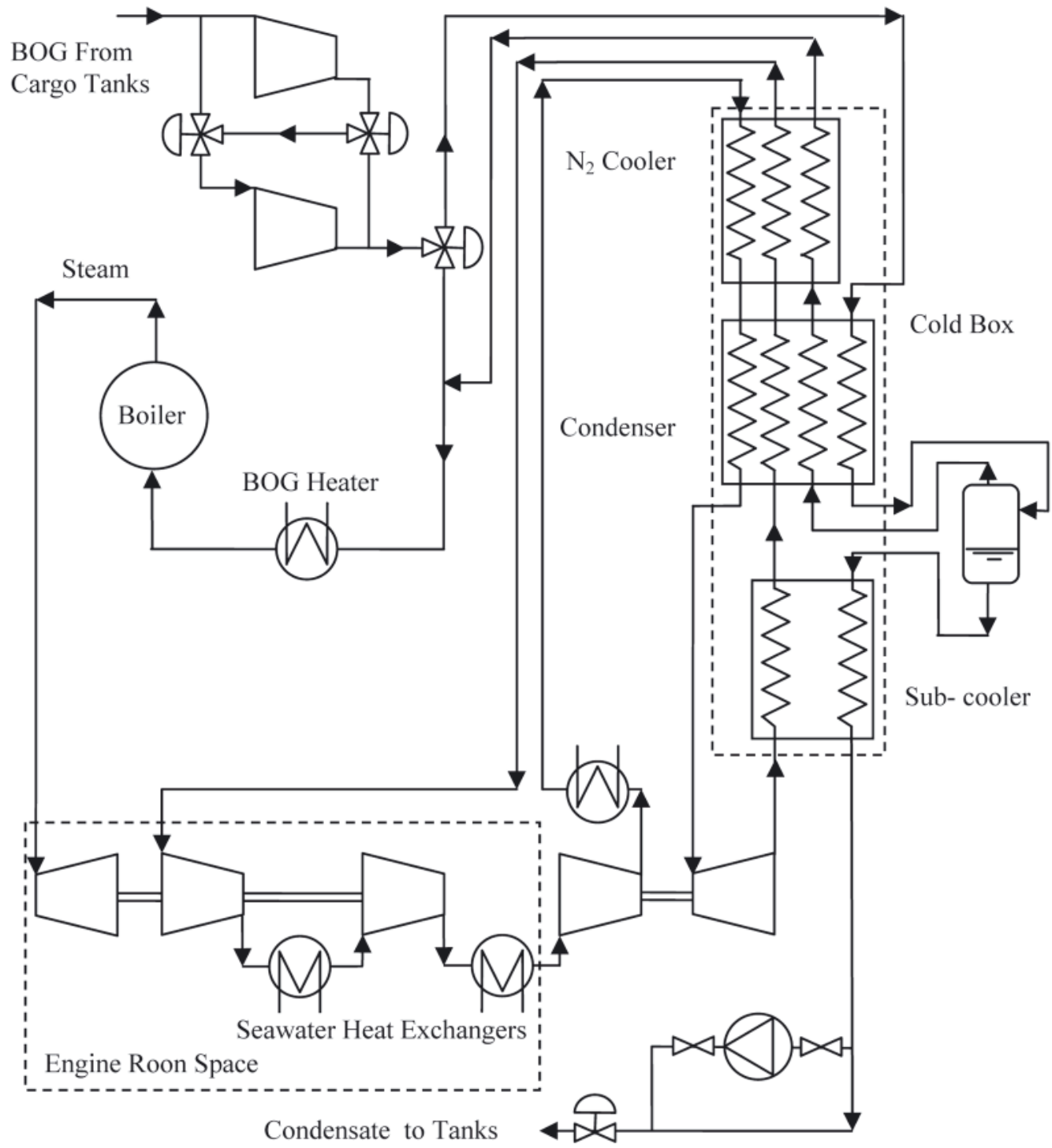

Fig. 3. BOG reliquefaction process flow diagram of the Jamal 
The plant is based on the reverse Brayton cycle using nitrogen as the working fluid. It was designed for a nominal reliquefaction capacity of 3 Tons/h based on a BOG rate (BOR) of $0.14 \%$ /day. The power required to process a nominal capacity is $3 \mathrm{MW}$.

Under normal conditions all the BOG is processed through the plant and a heavy fuel is used for propulsion, burned in boilers to produce steam for the turbines. In case of failure of the reliquefaction plant BOG is sent to the boiler to generate steam for the turbines, the ship is operated as a conventional tanker.

The cooling power is obtained from the nitrogen circulating in a closed reverse Brayton cycle. A schematic of the plant is depicted Fig. 3. The $\mathrm{N}_{2}$ is compressed to 35 bar by three-stage centrifugal compressors with intercooling by means of sea water. Once compressed it is introduced into a cold box, which houses most of the cryogenic equipment. This consists of three sections: the nitrogen cooler, a condenser and a subcooler. Here the nitrogen is cooled before entering an expander, where it makes the expansion from 35 bar to 6.5 bar. Thus obtaining the cold current that leads to the cold box upstream to subcool the LNG and the $\mathrm{N}_{2}$ before undergoing expansion.

The energy for the first two stages of compression of $\mathrm{N}_{2}$ is obtained from a turbine powered by steam from the main boiler, while the third stage of compression is the energy recovered in the expander. The problem with this is the pressure loss that occurs in the nitrogen cycle, to travel great distances to the engine room to be driven by the turbine.

BOG system is composed by 2 centrifugal compressors, which can be batch or parallel as required. When demand is high BOG compressors operate in both tandem and when it is low or the BOG is burned in boilers as in a traditional LNG, are arranged in parallel and the other remain in stand-by.

To condition the BOG for reliquefaction, it is compressed to 4.5 bar with the two compressors in series. As the BOG passes through the cold box and the heat exchange performed on the $\mathrm{N}_{2}$, it condenses and heads toward the separator gas/liquid. Here the non-condensable gases of the condensed BOG are separated. Condensable gases are directed against the current in the condenser and the nitrogen heat exchanger, to act as a coolant, conditioning it to turn for combustion in the steam boiler. The BOG condensate is then sent to the sub-cooler and back to the tanks by pressure difference. In certain processes, where the pressure of the condensed BOG is not sufficient to overcome the column of LNG of the tanks, there is a pump that raises the pressure.

Except in the case of BOG compressors, which are used as much in plant mode as in conventional mode, the system implemented on the Jamal has used no additional redundancy methods for the reliquefaction plant. Instead, the steam boiler has the same redundancy as that of any conventional carriers.

\subsection{Tractebel Gas Engineering TGE}

As a result of heightened awareness that TGE liquefaction technologies has, this process is also based on reverse Brayton cycle with nitrogen. Fig. 4 shows the diagram of this process. The plant has been designed for a carrier of $228000 \mathrm{~m}^{3}$, with a BOR of $0.14 \% /$ day, which means $6.25 \mathrm{t} / \mathrm{h}$.

The BOG from the tanks is compressed by a centrifugal compressor at a pressure ranging from about 3 to $6 \mathrm{bar}$, and liquefied in the main heat exchanger by the cold current of $\mathrm{N}_{2}$ It is previously expanded to the pressure tank through a valve. For the start-up process, in cases where liquefaction of the BOG isn't achieved, the plant has a larger diameter valve to facilitate the exit. An exchanger is located at the entrance of the reliquefaction plant to condition the BOG by means of injecting LNG. In this way the inlet temperature is controlled in extreme cases and eases startups. This exchanger also acts as a pre-cleaner to prevent liquid from entering the compressor.

The cooled nitrogen is compressed in a three-stage turbo compressor exchangers shell and tube to room temperature with seawater. It is then introduced into the heat exchanger until reaching temperatures of between $-80^{\circ} \mathrm{C}$ and $-110^{\circ} \mathrm{C}$.

The cooled nitrogen is sent via the expander, whose transmission shaft is connected to the third stage of compression named a Compander. Hence the nitrogen temperature reaches $-170^{\circ} \mathrm{C} /-180^{\circ} \mathrm{C}$ with expansion.

Due to the different boiling points of LNG components (ranging from $-196^{\circ} \mathrm{C}$ to $+36^{\circ} \mathrm{C}$ ), vaporization is not homogeneous: components with the lowest boiling point $\left(\mathrm{N}_{2}\right.$ and $\mathrm{CH}_{4}$ ) tend to evaporate in a more important amount than heavy components [ethane $(\mathrm{C} 2)$ and propane $(\mathrm{C} 3)$, and traces of i-butane (i-C4), n-butane (n-C4), i-pentane (i-C5) and n-pentane (n-C5)] [12]. This phenomenon is known as the aging of LNG and its main consequence is the change of the composition and its properties during the trip. In this plant, the incondensable BOG gases are injected into the cargo tanks for its reabsorption by a piping system. This prevents the enrichment of the load and maintains a relatively constant composition.

BOG and $\mathrm{N}_{2}$ equipment are separated by a bulkhead, ensuring safety while allowing the use of lower cost devices on the $\mathrm{N}_{2}$.

The control system is through a conventional PLC integrated into the architecture of the plant cargo system. The boot sequence is programmed to reach operating temperature in 2 hours from room temperature. The plant is designed to work 9-12 hours a day on a loaded voyage. During the period of operation the tanks are cooled and then remain stopped until the pressure increases again and the control system proceeds to initiate the boot sequence. Once the plant is cooled, the sequences of stop/start are reduced to one hour.

The installed power for compression of $\mathrm{N}_{2}$ is of $4.700 \mathrm{~kW}$ and $2 \times 330 \mathrm{~kW}$ for the compression of the BOG. The power recovered in the expander is of the order of $1200 \mathrm{~kW}$. The water flow required for the intermediate cooling of $\mathrm{N}_{2}$ increases to approximately $700 \mathrm{~m}^{3} / \mathrm{h}$. The total energy consumption is about $0.75 \mathrm{kWh} / \mathrm{kg}$ [13].

The redundancy of the compression equipment includes margins of tolerance of $5 \%$ and $25 \%$ for the cryogenic heat exchanger. A redundant system, that is, two compressors of equal capacity, is available for the compression of BOG. In the case of reliquefaction system failure, the plant has a combustion unit (CGU, Combustion Gas Unit) to maintain steady pressure in the tanks.

\subsection{Mark I}

This plant was developed by Hamworthy Gas System (HGS), based on the reverse Brayton cycle. Qatargas and ExxonMobil chose it as the reliquefaction system for the first Q-Flex ships of $210.000 \mathrm{~m}^{3}$, combined with a slow propulsion system. It's design is based on a BOR of approximately $0.14 \%$ /day of the cargo volume and has a maximum capacity of $6 \mathrm{t} / \mathrm{h}$ reliquefaction plant, with an approximate electric power consumption of 5.8 MW. A flowchart of the reliquefaction system is shown in Fig. 5.

The BOG at the entrance of the plant is pre-cooled in a heat exchanger by flashing a small stream of BOG condensate from the separator. Since the BOG is being heated when transferred from the LNG tanks to the plant suction, a pre-cooling allows for the temperature compensation before entering the 


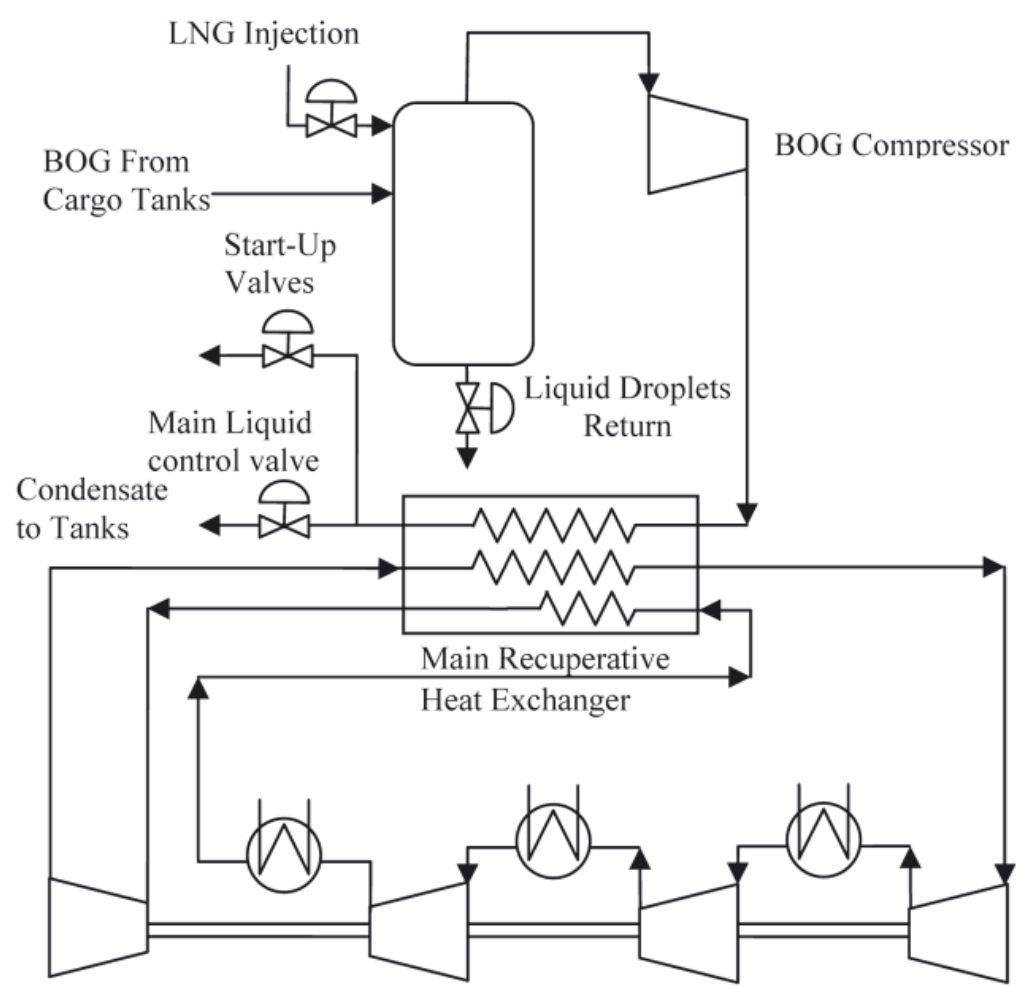

$\mathrm{N}_{2}$ Expander

3- Stage $\mathrm{N}_{2}$ Compressor

Fig. 4. Flow Diagram of the reliquefaction of TGE process

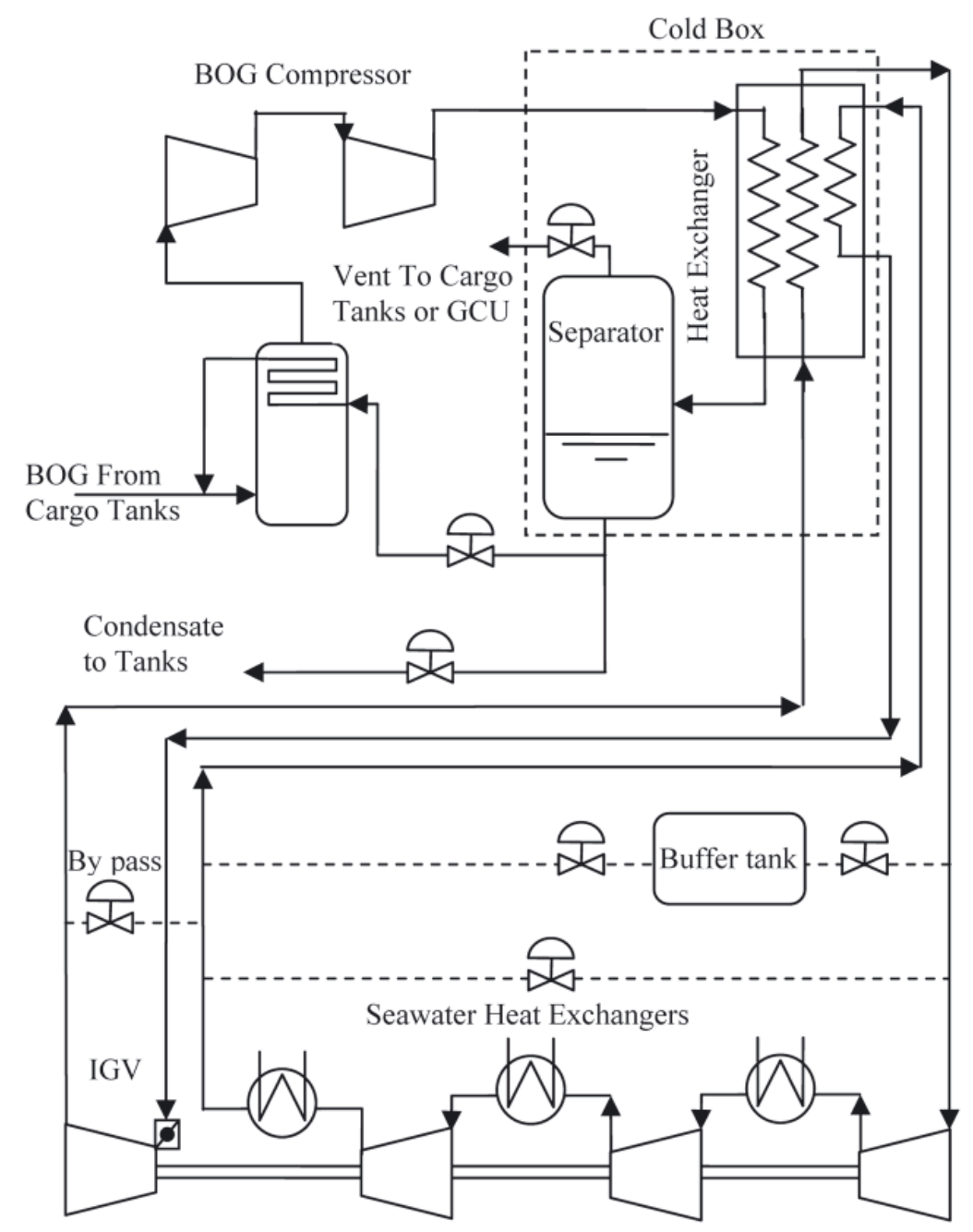

$\mathrm{N}_{2}$ Expander

3- Stage $\mathrm{N}_{2}$ Compressor

Fig. 5. Flow diagram of HGS Mark I reliquefaction process 
reliquefaction plant, thus maintaining a stable temperature at the entrance of the process. The pre-cooling heat exchanger is designed to remove any possible heavy components formed by condensation and in effect protect the compressors.

Precooled BOG is compressed to approximately 4.5 bar in two stages with centrifugal compressors with a capacity regulation by DGVs (diffuser guide vanes). This allows the variation of the flow of BOG through the compressors in order to adapt to BOR changes in the tanks and therefore control the pressure.

Once the BOG is compressed it is condensed counter current with the cold $\mathrm{N}_{2}$ in the cryogenic heat exchanger. The BOG condensate is collected in a separator to remove noncondensable gases, and from here as a result of the pressure difference with the cargo tanks, is returned. The cryogenic heat exchanger and the separator form a single insulated cold box to minimize the heat input.
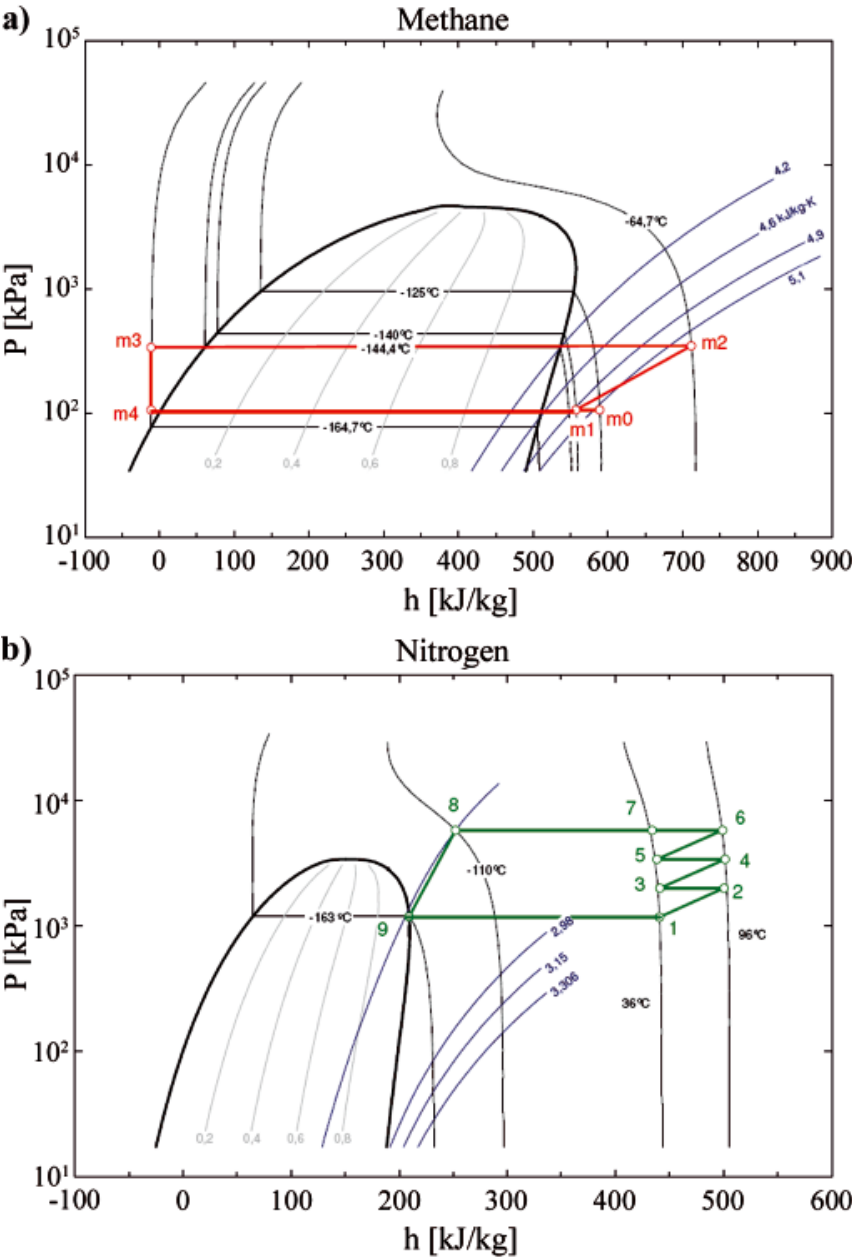

Fig. 6. a) Mollier diagram of different stages of $B O G$ in the reliquefaction process; b) Mollier diagram of the Brayton refrigeration cycle

Fig. 6(a) shows the different stages of cooling process by the BOG. The process $(\mathrm{m} 0-\mathrm{m} 1)$ is the pre-cooling of the BOG on entry to the plant, before the double compression (m1-m2). This pre-cooling is due to the evaporation $(\mathrm{m} 4-\mathrm{m} 1)$ of the flashed fraction of BOG condensate $(\mathrm{m} 3-\mathrm{m} 4)$.

In the reverse Brayton cycle, in terms of design, $\mathrm{N}_{2}$ is compressed to 58 bar in three-compression stage with intercooling and cooled down to $-110^{\circ} \mathrm{C}$ in the cryogenic heat exchanger. In the expansion, the pressure drops to 14.5 bar and the temperature to $-163^{\circ} \mathrm{C}$.

The plant's control software is designed to handle all the changes in the BOG. The control can be summarized in two ways: start-up and normal operation. In start-up mode a pre-cooling of the heat exchanger is carried out at a rate of $-2{ }^{\circ} \mathrm{C} / \mathrm{min}$ to a temperature close to $-163^{\circ} \mathrm{C}$, operating only the $\mathrm{N}_{2}$ cycle. Once the pre-cooling is complete it passes to normal operating mode with the BOG compressor running to process the BOG. During normal operation, the expander outlet temperature is controlled to keep it as low as possible, but above the saturation limit. At the same time, the amount of circulating $\mathrm{N}_{2}$ is continuously controlled to meet the thermal demands of the BOG to condense.

To control the final expansion temperature of the plant it is equipped with three capacity control actuators: Buffer tank valves, Inlet guide vane (IGV) and bypass valve, arranged as shown in Fig. 5.

In medium and high work mode, the control of the reliquefaction capacity is achieved by varying the $\mathrm{N}_{2}$ mass flow circulating in the circuit, through the buffer tank connected between the suction and discharge with its corresponding valves.

If the cooling capacity is too low, the outlet temperature of the expander is increased and so opens the control valve of the nitrogen container located at stage 1 of the compressor suction and nitrogen is added to the Brayton cycle until the setpoint temperature at the outlet of the expander is achieved. If, however, the cooling capacity is too high, the expander outlet temperature decreases, thus opening the nitrogen container's control valve located after the last compression cooling and nitrogen is removed from the cycle until the setpoint temperature is reached at the exit of the expander.

The nitrogen container, located on deck, is designed to engender a sufficient volume to store the N2 at room temperature and an intermediate pressure between suction and discharge. This pressure varies depending on the work situation of the plant. If the plant operates near the nominal point, the pressure in the container will be closer to the suction pressure of Stage 1, while if working part-load the pressure value is close to the discharge.

At low load operation, to control the final temperature of expansion, cross-sectional area is reduced via the inlet guide vane mediate (IGV) of the expander. This ensures the expansion outside the zone of saturation. If this control loop is not enough the by-pass valve control loop opens it, introducing hot gas at the end of the expansion process.

For the control of flash gases produced in the separator, the plant installs an automatic gas purger which returns the gas to the tanks or send it to the CGU.

The process uses full redundancy for all rotating parts as specified by the regulations on international gas carrierss. The CGU is able to handle $150 \%$ of normal BOR, to ensure the treatment of BOG in case of total failure of the BOG reliquefaction system.

\subsection{Ecorel}

The Ecorel plant was developed by the Cryostar company for Q-Max ships of $266.000 \mathrm{~m}^{3}$, on the Qatargas-2 project. The operating principle is similar to the Mark I, HGS plant. A flowchart of the Ecorel plant is shown in Fig. 7. The plant has a reliquefaction capacity of $7 \mathrm{t} / \mathrm{h}$ of the BOG, with a power consumption of about $6 \mathrm{MW}$.

$\mathrm{BOG}$ is compressed in two-stages with centrifugal compressors equipped with capacity control by DGVs up to 4.8 bar. The compression between stages is cooled by a fraction of $\mathrm{N}_{2}$ from the $\mathrm{BOG}$ condenser, which reduces the required compression work. Before passing to the condenser 


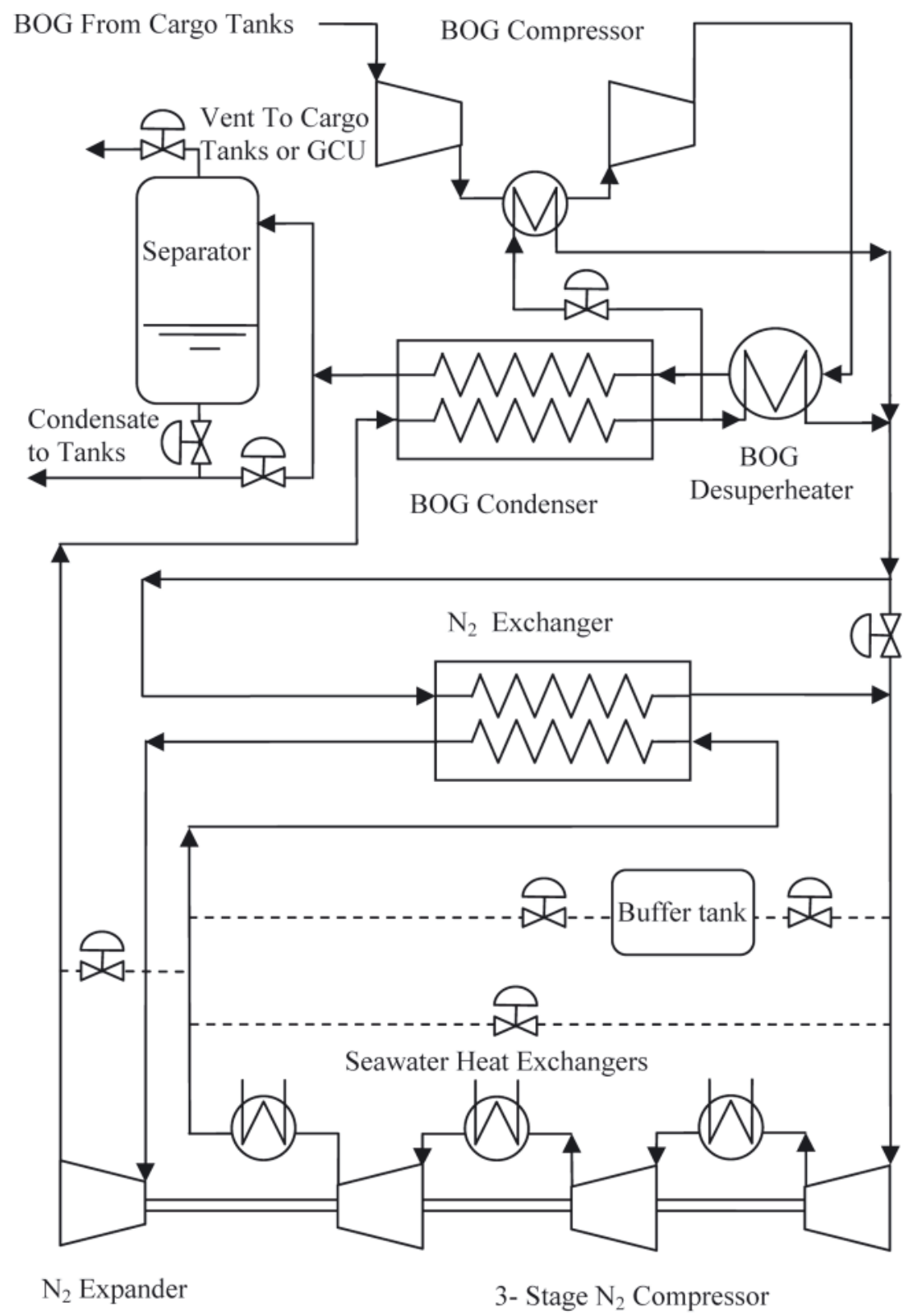

Fig. 7. Flow diagram of the Cryostar Ecorel reliquefaction plant

the compressed BOG is cooled in a heat exchanger constructed of stainless steel. This exchanger gives strength to the plant, since the stainless steel heat exchanger can better absorb fluctuations in temperature of the process while protecting the BOG condenser, made of aluminum plates. The two heat exchangers are individually isolated and not in a cold box, as in the Mark I, HGS plant.

In terms of design, the $\mathrm{N}_{2}$ is compressed to 47 bar in three compression stages with intercooling and cooled down to $105^{\circ} \mathrm{C}$ before it expands to 9.5 bar and $-168^{\circ} \mathrm{C}$.

The BOG condensate is slightly sub-cooled, so it can be returned to the tanks back directly, without passing through the separator. For cargoes with higher content of $\mathrm{N}_{2}$ in the BOG, the system switches to partial reliquefaction. In this mode for a BOG compressor and phase mixture coming from the condenser is redirected to a separator. Depending on the pressure of the cargo tanks, the vapor separator is returned back to the tank or CGU.

The variation of cooling capacity of the plant is controlled in a manner similar to the HGS system. However, Ecorel's plant's system has additional by-passes in all the $\mathrm{N}_{2}$ cycle operation that gives a better operational capacity.

\subsection{Mark III}

HGS designed Mark III as an improvement on the previous Mark I, with the intention of reducing power consumption and completely with the Ecorel Cryostar plant. Fig. 8 shows the process flow diagram.

In Mark III BOG compression is performed at temperatures close to room temperature, using 3 centrifugal compressors with intercooling with seawater. Compression at room temperature is a result of heat transfer given by the BOG in a heat exchanger at the entrance of the plant, with a stream of $\mathrm{N}_{2}$ from the cooler of the third compression stage. The advantages of compression at room temperature are as follows:

- Installation of conventional compressors

- The use of regular oil

- Removal of heat of BOG compression with seawater

- Reduces the losses of exergy in the ColdBox.

- Allows to condense BOG at high pressure

The $\mathrm{N}_{2}$, as in Marck I, is compressed into 3 stages with centrifugal compressors. After third stage cooling, the current is divided into two different streams. One stream is 


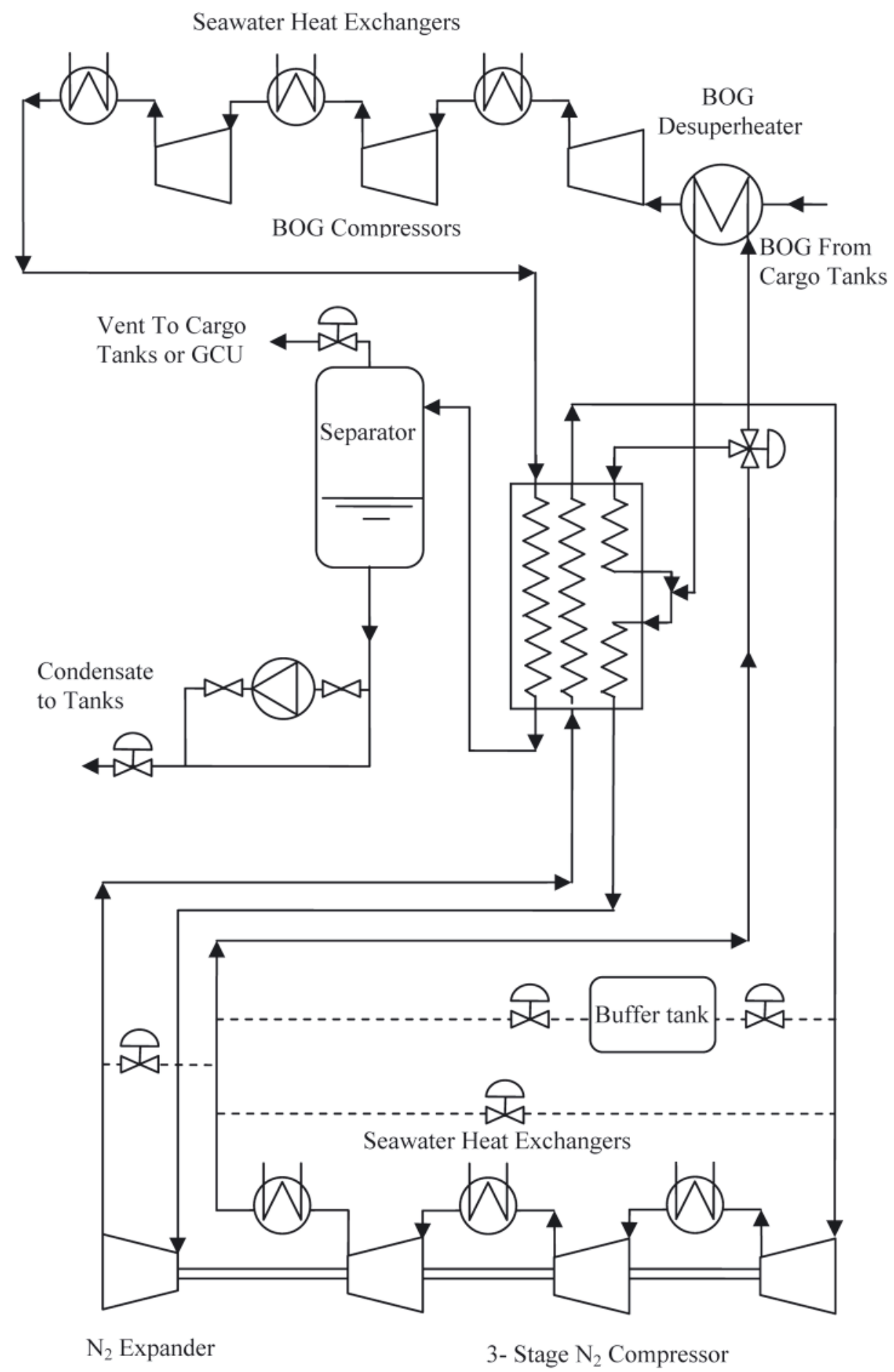

Fig. 8. Flow Diagramof the Cryostar Ecorel reliquefaction process

used to preheat the BOG and the other is driven to the hot part of the cold box. After $\mathrm{N}_{2}$ exchanged heat with the BOG coming into the plant, the two streams are mixed again and reintroduced into the cold box. With this implementation and according to manufacturer's specifications [14], for a Q-Max ship considering the BOG $100 \%$ methane, a requirement of approximately $5.5 \mathrm{MW}$ is needed for reliquefaction of $7 \mathrm{t} / \mathrm{h}$.

\subsection{Laby-GI Mark III}

This plant is designed to be implanted in combination with a propulsion system with a 2 -stroke dual combustion engines.
The reliquefaction plant is the same as Mark III, with the exception of the compressors and the integration of the fuel system compressed to feed the dual motors. The principle scheme is shown in Fig. 9. The BOG compression system is replaced by a vertical reciprocating compressor manufactured by Burckhardt called Laby ${ }^{\circledR}$-GI. This compressor is if 5 stages type, of which the first two are part of the reliquefaction plant. The BOG is compressed in the first and second stages up to 5-6 bar and the pressure of the other following 3 is risen to 300 bar. Such high pressure is necessary to ensure injection into the combustion chamber of the dual engines.

BOG compression at room temperature is achieved, as in Mark III, as a result of heat transfer experienced by the BOG in a heat exchanger at the entrance of the plant with 


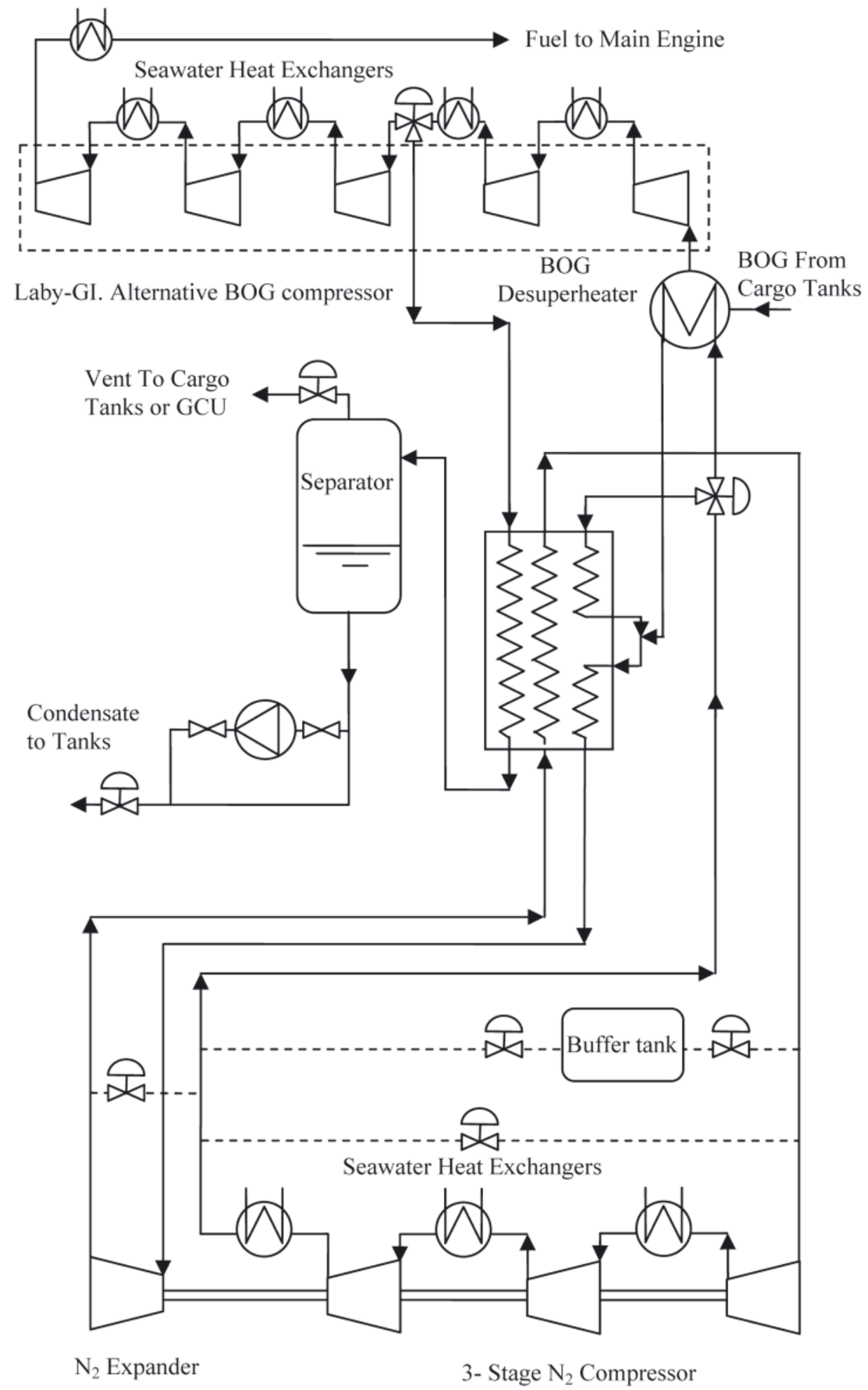

Fig. 9. Flow Diagram of the Laby-GI Mark III HGS reliquefaction process

a stream of $\mathrm{N}_{2}$ from the cooler of the third stage compression. This configuration ensures that the compression heat can be dissipated through the cooling water in intercoolers.

When the main engine works in gas mode, the BOG is compressed to 300 bar by the compressor and is not processed by the reliquefaction plant. If excess of BOG is produced, after the second stage of compression, the BOG is diverted for condensation in the reliquefaction plant. When the engine operates in HFO the entire BOG is processed by the plant.

When in ballast, the propulsion system can go in HFO mode and with the plant running for the liquefaction of BOG in order to keep the cargo tanks cool or use the BOG to fuel the engine.

\subsection{Laby-GI TGE}

This plant has a special feature meaning it does not use the Brayton cycle, but a cascade process with ethylene and propylene of higher thermodynamic efficiency. Fig. 10 schematically shows the process. Tractebel Gas Engineering and Burckhardt developed the reliquefaction plant with the intention of combining the propulsion system with dual engines 


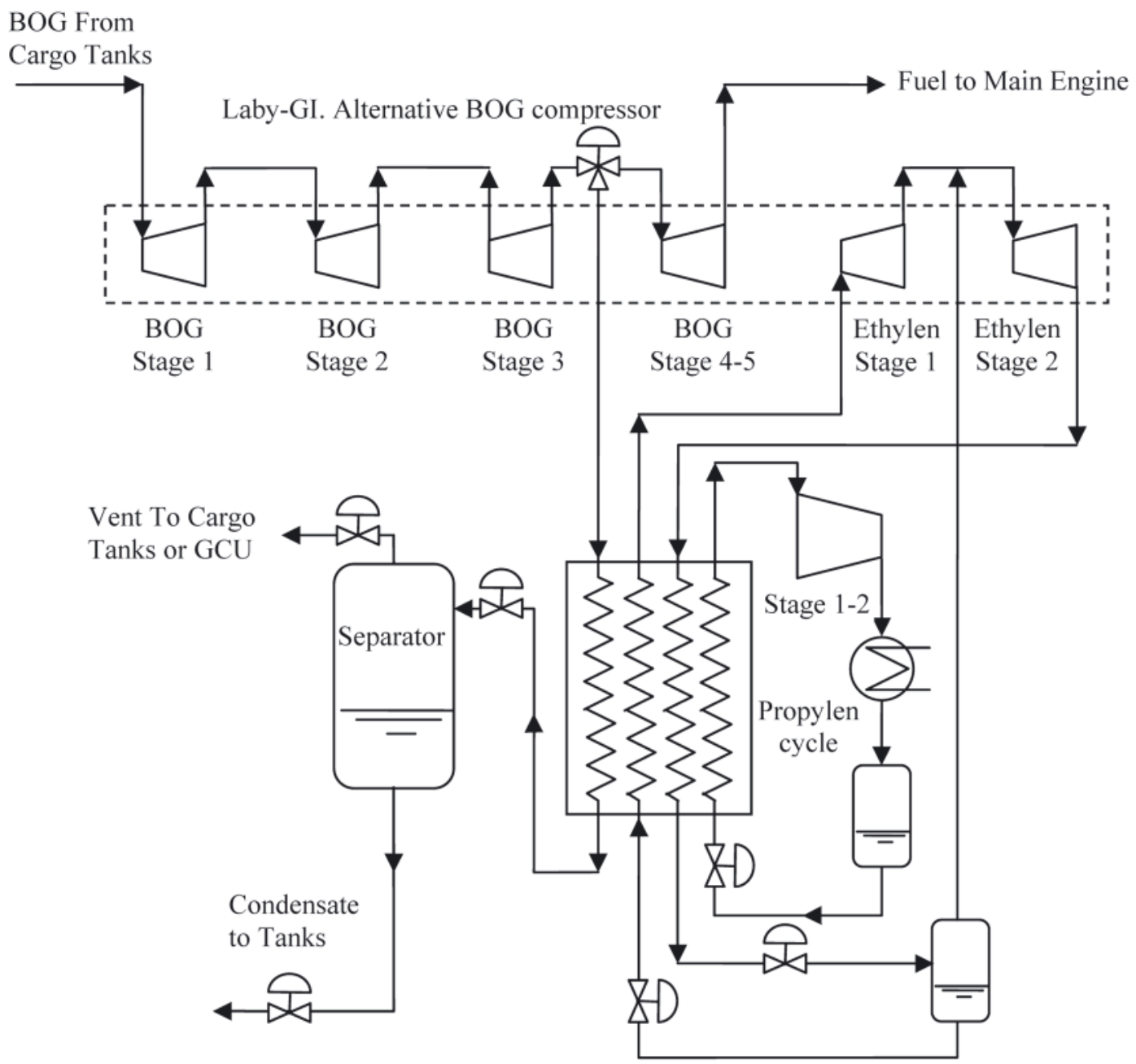

Fig. 10. Outline of the cascade process for the TGE's liquefaction of BOG

for LNG carriers with a capacity of between $170.000 \mathrm{~m}^{3}$ and $210.000 \mathrm{~m}^{3}$.

The BOG compression process both for the reliquefaction as for burning in the dual motors, and compression of ethylene that corresponds to the cascade cycle, is carried out with the Burckhardt's Laby-GI compressor. Fig. 11 shows the distribution of the compression stages and structure.

In reliquefaction mode, the $\mathrm{BOG}$ from the tanks is compressed in three stages up to 45 bar and condensed to $-100^{\circ} \mathrm{C}$ by a cycle of ethylene of double compression with intercooling. The ethylene is condensed at $-30^{\circ} \mathrm{C}$ and 19 bar with propylene in the same exchanger as where condensation of the BOG takes place. Propylene compression is performed in a separate screw compressor and condensed at 17 bar and $40^{\circ} \mathrm{C}$ with seawater.

The BOG condensate is flashed in a gas/liquid separator and returned to the tanks.

The variable for the operation of the Laby-GI compressor is the feed pressure of the dual engines. It is capable of varying the feed pressure between $150 \div 300$ bar, depending on the engine load. When the engine load does not consume all of the BOG demand, the reliquefaction plant is put into operation.

\section{COMPARISON OF PROCESSES}

In the descriptive analysis of different manufacturers' reliquefaction processes, data of the various capabilities and power consumption was provided, as well as other technical and business data. The information is based primarily on technical

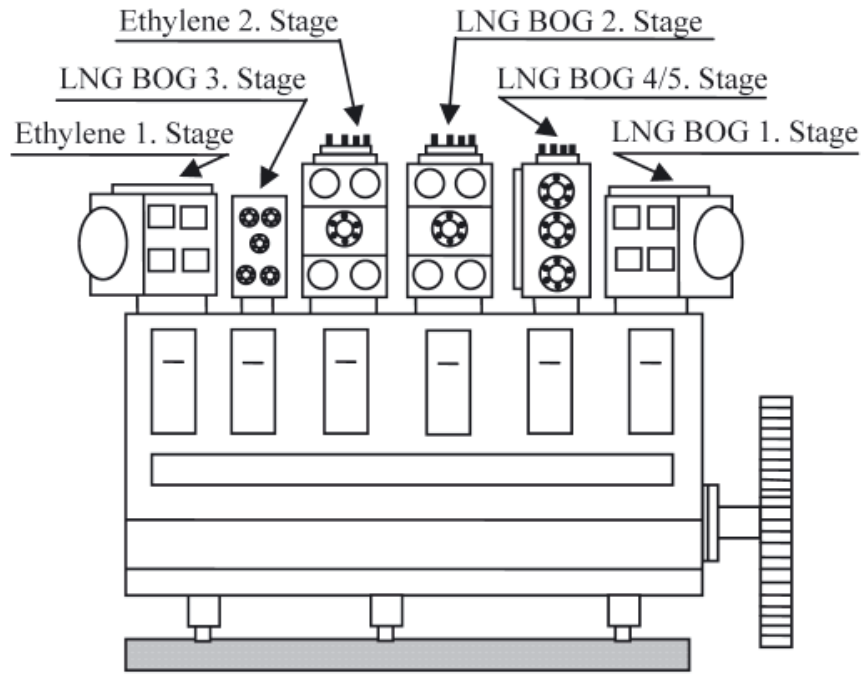

Fig. 11. Representation of Burckhardt's Laby-GI compressor and the distribution of the BOG compression stages and cascade modes

information provided by plant manufacturers and equipment suppliers. Tab. 2 summarizes this information intended to assess the tendencies in the implementation of reliquefaction processes.

Despite it's high energy consumption, the choice of the Brayton cycle for reliquefaction is characterized by its compactness and robustness, its simplicity and it's small number of additional equipment. The objective of lowering the 
Tab. 2. Some relevant data regarding capacities, plant power, as well as some useful technical data of the reliquefaction plant architectures provided by the manufacturers

\begin{tabular}{|c|c|c|c|c|c|c|c|}
\hline & \multicolumn{7}{|c|}{ Reliquefaction Plant } \\
\hline & Jamal & TGE & Mark I & EcoRel & Mark III & $\begin{array}{l}\text { Mark III } \\
\text { Laby-GI }\end{array}$ & $\begin{array}{c}\text { TGE } \\
\text { Laby-GI }\end{array}$ \\
\hline SUPPLIER & OsakaGas & Tractebel & HGS & Cryostar & HGS & HGS & Tractebel \\
\hline YEAR & 2000 & 2004 & 2006 & 2008 & 2008 & 2009 & 2009 \\
\hline \begin{tabular}{c|} 
CICLO \\
Refrigerant \\
Work press. (bar) \\
Expansion temp \\
\end{tabular} & $\begin{array}{c}\text { Brayton } \\
\mathrm{N}_{2} \\
35-6.5 \\
--\end{array}$ & $\begin{array}{c}\text { Brayton } \\
\mathrm{N}_{2} \\
-- \\
-170^{\circ} \mathrm{C} \\
\end{array}$ & $\begin{array}{l}\text { Brayton } \\
\mathrm{N}_{2} \\
58-14.5 \\
-163^{\circ} \mathrm{C} \\
\end{array}$ & $\begin{array}{c}\text { Brayton } \\
\mathrm{N}_{2} \\
47-9.5 \\
-168^{\circ} \mathrm{C} \\
\end{array}$ & $\begin{array}{l}\text { Brayton } \\
\mathrm{N}_{2} \\
58-14.5 \\
-163^{\circ} \mathrm{C} \\
\end{array}$ & $\begin{array}{l}\text { Brayton } \\
\mathrm{N}_{2} \\
58-14.5 \\
-163^{\circ} \mathrm{C} \\
\end{array}$ & $\begin{array}{c}\text { Cascade } \\
\mathrm{C}_{2} \mathrm{H}_{4} / \mathrm{C}_{3} \mathrm{H}_{6} \\
1-19 / 1.7-17 \\
-105 /-35^{\circ} \mathrm{C} \\
\end{array}$ \\
\hline $\begin{array}{c}\text { BOG CYCLE } \\
\text { Compressor type } \\
\mathrm{N}^{\circ} \text { Compressors } \\
\text { Compress. press } \\
\text { Suction temp } \\
\text { Observations }\end{array}$ & $\begin{array}{c}\text { Centrifuge } \\
2 \\
4.5 \text { bar } \\
-140^{\circ} \mathrm{C}\end{array}$ & $\begin{array}{c}\text { Centrifuge } \\
1 \\
3-6 \text { bar } \\
-\end{array}$ & $\begin{array}{c}\text { Centrifuge } \\
2 \\
4.5 \mathrm{bar} \\
-145^{\circ} \mathrm{C}\end{array}$ & $\begin{array}{c}\text { Centrifuge } \\
2 \\
4.8 \mathrm{bar} \\
-120^{\circ} \mathrm{C} \\
\text { Interm. Refrig. } \\
\text { with } \mathrm{N}_{2} \\
\end{array}$ & $\begin{array}{c}\text { Centrifuge } \\
3 \\
- \\
\text { Room tem } \\
\text { Interm. Refrig } \\
\text { sea water } \\
\end{array}$ & $\begin{array}{c}\text { Alternative } \\
2 \text { stages } \\
5-6 \text { bar } \\
\text { Room tem } \\
\text { Interm. Refrig } \\
\text { sea water }\end{array}$ & $\begin{array}{c}\text { Alternative } \\
3 \text { stages } \\
45 \text { bar } \\
- \\
\text { Interm. Refrig } \\
\text { sea water }\end{array}$ \\
\hline $\begin{array}{l}\text { CAPACITY } \\
\text { Liquefaction }\end{array}$ & $\begin{array}{c}3 \mathrm{t} / \mathrm{h} \\
0.83 \mathrm{~kg} / \mathrm{s}\end{array}$ & $\begin{array}{c}6.25 \mathrm{t} / \mathrm{h} \\
1.74 \mathrm{~kg} / \mathrm{s} \\
\end{array}$ & $\begin{array}{c}6 \mathrm{t} / \mathrm{h} \\
1.67 \mathrm{~kg} / \mathrm{s}\end{array}$ & $\begin{array}{c}7 \mathrm{t} / \mathrm{h} \\
1.94 \mathrm{~kg} / \mathrm{s}\end{array}$ & $\begin{array}{c}7 \mathrm{t} / \mathrm{h} \\
1.94 \mathrm{~kg} / \mathrm{s}\end{array}$ & 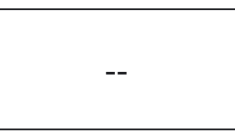 & 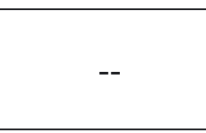 \\
\hline $\begin{array}{c}\text { POWER } \\
\mathrm{kW}{ }^{*} \text { Installed } \\
\mathrm{kWh} / \mathrm{kg}_{\text {BOG }}\end{array}$ & $\begin{array}{c}3000 \\
1\end{array}$ & $\begin{array}{c}5030^{*} \\
0.75\end{array}$ & $\begin{array}{c}5.800 \\
0.96\end{array}$ & $\begin{array}{c}6.000 \\
0.86\end{array}$ & $\begin{array}{c}5.500 \\
0.78\end{array}$ & $\begin{array}{l}-- \\
--\end{array}$ & $\begin{array}{l}-- \\
--\end{array}$ \\
\hline $\begin{array}{c}\text { SHIP } \\
\text { Capacity }\left(\mathrm{m}^{3}\right) \\
\text { Propulsion }\end{array}$ & $\begin{array}{l}135.000 \\
\text { Steam } \\
\text { turbine }\end{array}$ & \begin{tabular}{|c|}
228.000 \\
low speed \\
2-stroke \\
diesel
\end{tabular} & \begin{tabular}{|c} 
Q-flex \\
210.000 \\
low speed \\
2-stroke \\
diesel \\
\end{tabular} & $\begin{array}{c}\text { Q-Max } \\
266.000 \\
\text { low speed 2- } \\
\text { stroke } \\
\text { diesel } \\
\end{array}$ & $\begin{array}{c}\text { Q-Max } \\
266.000 \\
\text { low speed 2- } \\
\text { stroke } \\
\text { diesel } \\
\end{array}$ & $\begin{array}{c}-- \\
\text { low speed 2- } \\
\text { stroke } \\
\text { dual fuel } \\
\end{array}$ & $\begin{array}{c}210.000 \\
\text { low speed 2- } \\
\text { stroke } \\
\text { dual fuel } \\
\end{array}$ \\
\hline
\end{tabular}

power requirements associated with an increased reliquefaction ability in recent years, contributes to an ever-greater complexity of the process and a larger number of necessary equipment. This causes the assessment of the cascade reliquefaction technology developed by TGE, where the process is more efficient due to the phase change. A noteworthy disadvantage is that it requires more safety instrumentation than Brayton cycles due to the inherent use of refrigerant fuels as working fluids. Furthermore, the use of different levels of temperature leads to a more complex and costly installation in both its implementation and maintenance.

\section{CONCLUSIONS}

Conducting a descriptive comparison of different technologies has become necessary following the increasing number of manufacturers who seek to apply these new techniques on ships. The knowledge of these is of great importance in order to provide selection criteria and make the correct decisions with the responsibility of selecting the most efficient technology. Based on the conducted review, it can be concluded that the technological contributions of the last 4 years are headed towards the combination of reliquefaction propulsion with dual engine systems, with the aim of maximizing flexibility in the exploitation strategy of LNG ships operating at high efficiency and comply with legislation regarding fuel emissions. Furthermore, the cascade based reliquefaction technology has become a serious alternative to the Brayton cycle due to its greater efficiency and lower maintenance costs despite of some drawbacks such as the use of fossil fuel based refrigerants and higher implementation and maintenance costs.

\section{BIBLIOGRAPHY}

1. Bortnowska M.: Development of new technologies for shipping natural gas by sea. Polish Maritime Research. No 3(61) Vol 16, pp 70-78, 2009

2. Küver M, Clucas C, Fuhrmann N.: Evaluation of propulsion options for $L N G$ carriers. In: The 20th international conference and exhibition for the LNG, LPG and natural gas industries (GASTECH 2002).

3. Romero Gómez, J., Ferreiro García, R., Carbia J.: Análisis de la relicuación del boil off en buques de GNL Alternativa al proceso basado en el ciclo Brayton de refrigeración. Ingeniería Quimica No.462, pp 164-176, 2008.

4. Romero Gómez, J., Ferreiro García, R., Bouzón Otero, R., De Miguel Catoira, A.: Relicuación del boil-off en buques LNG: principios tecnológicos. Ingenieria Quimica, Vol 504, pp. 44-50, 2012.

5. Thomas N. Anderson, Mark E. Ehrhardt,Robert E. Foglesong, Tom Bolton, David Jonesc and Andy Richardson: Shipboard Reliquefaction for Large LNG Carriers. In: Proceedings of the 1st Annual Gas Processing Symposium. (2009) http://www. nt.ntnu.no/users/skoge/prost/proceedings/gas-processing-doha2009/fscommand/po03.pdf; (Accessed 24/11/2012)

6. Romero, J., Orosa, J.A., Oliveira, A.C.: Research on the Brayton cycle design conditions for reliquefaction cooling of $L N G$ boil off. Journal of Marine Science and Technology, pp 1-10, 2012.

7. Younggy Shin, Yoon Pyo Lee: Design of a boil-off natural gas reliquefaction control system for $L N G$ carriers. Applied Energy Vol. 86, pp. 37-44, 2009.

8. Daejun Chang, Taejin Rhee, Kiil Nam, Kwangpil Chang, Donghun Lee, Samheon Jeong: A study on availability and safety of new propulsion systems for LNG carriers. Reliability Engineering and System Safety, Vol. 93, pp. 1877- 1885, 2008.

9. Chang Kwang Pil, Marvin Rausand, Jřrn Vatn: Reliability assessment of reliquefaction systems on LNG carriers. 
Reliability Engineering and System Safety Vol. 93, pp. 13451353, 2008.

10.Barclay, M.A., Yang, CC.: Offshore LNG: The Prefect Starting Point for 2-Phase Expander. Offshore Technology Conference, May 2006.

11. Yoneyama H, Irie T, Hatanaka N.: The first BOG reliquefaction system on board ship in the world "LNG Jamal". In: The 22nd world gas conference, Tokyo, Japan. 2003

12.Mario Miana, Rafael del Hoyo, Vega Rodrigálvarez, José Ramón Valdés, Raúl Llorens: Calculation models for prediction of Liquefied Natural Gas (LNG) ageing during ship transportation. Applied Energy Vol. 87, pp. 1687-1700, 2010.

13.Gerdsmeyer, K-D, Harry Isalski, W.(2004) On-board reliquefaction for lng ships. http://www.ivt.ntnu.no/ept/fag/ tep4215/innhold/LNG\%20Conferences/2005/SDS_TIF/050202. pdf; (Accessed 24/11/2012).

14.Hamworthy Ltd., LNG Shipping Operations 27th Sept. 2006. Hamworthy Reliquefactión \& Regasification systems on $L N G$ carriers. http://www.thedigitalship.com/powerpoints/SMM06/ lng/Reidar\%20Strande,\%20Hamworthy.pdf; (Accessed 24/11/ 2012).

\section{CONTACT WITH THE AUTHORS}

J. Romero Gómez*), Ph. D., M. Romero Gómez, Ph. D.,

Department of Energy and Marine Propulsion, ETSNM, University of A Coruna, ETSNM,

Paseo de Ronda 51,

A Coruna 15011, SPAIN.

R. Ferreiro Garcia, Prof.,

Department of Industrial Engineering, ETSNM,

A. De Miguel Catoira, Ph. D.,

Department of Energy and Marine Propulsion, ETSNM,

*) Corresponding author:

e-mail: j.romero.gomez@udc.es, phone: +34 9811670004233 ,

fax: +34 981167100 